\title{
El impacto de un clúster de frutos secos en los actores y en el territorio de la Norpatagonia argentina. Primera aproximación
}

\section{Nuts Cluster Impact on Argentine North Patagonia Actors and Territory. First Approach}

\author{
Maximiliano Hadad* (iD https://orcid.org/0000-0003-0091-0787 \\ Germán González ${ }^{* *}$ (D) https://orcid.org/0000-0002-9341-8654 \\ Santiago Ferro Moreno ${ }^{* *}$ (D) https://orcid.org/0000-0001-5131-3662
}

\begin{abstract}
Resumen
Las iniciativas para mejorar la competitividad sectorial son recurrentes en América Latina, canalizadas a menudo en estrategias formales e informales tipificadas como clústeres en sus distintas acepciones. En este contexto, la evaluación del impacto sobre la competitividad de las empresas y el desarrollo territorial se torna necesaria. En Argentina, las experiencias son variadas, en general con poca información sobre el impacto real. El objetivo del artículo es ofrecer una evaluación exploratoria del impacto de un incipiente clúster de frutos secos en una región cuya actividad tradicional se encuentra en crisis. La metodología es de carácter retrospectivo siguiendo los lineamientos que propusieron Gertler, Martínez, Premand, Rawlings y Vermeersch en 20II. Tras la discusión sobre el escenario contrafactual, se detallan la evolución histórica del clúster, sus objetivos, los proyectos, la cadena de valor del sector y se evalúan sus impactos. Las principales conclusiones son que el acceso, el caudal y la calidad de la información que ha circulado dentro del clúster han tenido efectos significativos y positivos en el desempeño. Los impactos en el territorio resultan positivos, aunque el tiempo trascurrido para la evaluación es aún breve. La principal dificultad del clúster se encuentra en la escasez de financiamiento, lo cual limita sus posibilidades de crecimiento.

Palabras clave: clúster; desempeño; impacto; agricultura; Patagonia.
\end{abstract}

\section{Abstract}

Initiatives to improve sectoral competitiveness are recurrent in Latin America, mainly channeled into formal and informal strategies classified as clusters, in their different meanings. In this context, the evaluation of the impact on the competitiveness of enterprises and territorial development becomes necessary. In Argentina, there are varied experiences, in general with little information on the real impact. The objective of the work has been to offer an exploratory evaluation of the impact of the incipient nut cluster in a region whose traditional activity is in crisis. The methodology was retrospective following the guidelines proposed in $20 \mathrm{II}$ by Gertler, Martínez, Premand, Rawlings y Vermeersch. After the discussion of the counterfactual scenario, the paper describes the historical evolution of the cluster, the cluster's objectives and projects, the sector's value chain and the impacts. The main conclusions reached are that access, flow and quality of information that has been circulating within the cluster has had significant and positive effects on performance. The impacts on the territory are positive, although the time for evaluation is still short. The main difficulty of the cluster is the scarcity of funding which limits its growth possibilities. Keywords: cluster; performance; impact; agriculture; $\mathrm{Pa}-$ tagonia.

Cómo citar: Hadad, M., González, G., y Ferro Moreno, S. (2020). El impacto de un clúster de frutos secos en los actores y en el territorio de la Norpatagonia argentina. Primera aproximación. región y sociedad, 32, e I 273. doi: I0.22 I 98/rys2020/32/I273

* Universidad Nacional del Sur, Departamento de Economía. San Andrés 800-Campus Altos de Palihue, 8000 Bahía Blanca, Buenos Aires, Argentina. Correo electrónico: jmhadad@hotmail.com.ar

** Autor para correspondencia. Universidad Nacional del Sur - Consejo Nacional de Investigaciones Científicas y Técnicas, Instituto de Investigaciones Económicas y Sociales del Sur. San Andrés 800-Campus Altos de Palihue, 8000 Bahía Blanca, Buenos Aires, Argentina. Correo electrónico: ghgonza@uns.edu.ar

*** Universidad Nacional de La Pampa, Facultad de Agronomía. Ruta 35, Km. 334, L6300 Santa Rosa, La Pampa, Argentina. Correo electrónico: sferromoreno@agro.unlpam.edu.ar

Recibido: 3 de diciembre de 2019

Aceptado: 20 de julio de 2020

Liberado: 21 de agosto de 2020

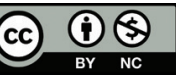




\section{Introducción}

Las políticas de promoción de aglomeraciones productivas surgen en América Latina como estrategias nacionales de sustitución de importaciones (Örjan, Lindquist y Ketels, 2003). El concepto de clúster fue el que adquirió mayor predominio (Palau y Napolitano, 2011), al punto de que todos los países de la región sostienen programas basados en esta idea (Fernández, Amin y Vigil, 2008; Kataishi, Romano y Valle, 2017).

Las iniciativas clúster buscan impulsar el desarrollo del tejido productivo de las regiones para favorecer la competitividad (Perdomo y Malaver, 2003) fomentando entre los agentes involucrados su interacción. Kataishi, Romano y Valle (2017) plantean que dicha interacción se enmarca en la visión de que las economías locales pueden pensarse como sistemas regionales de innovación que generan potencialidades que no se dan de manera natural a partir de mecanismos de mercado, lo cual se constituye en objetivo e instrumento de políticas públicas (Dirven, 2006). En Argentina, las experiencias son variadas, en general con poca información sobre el impacto real. Algunos antecedentes de estudios descriptivos de clústeres alimentarios en Argentina son: Bongiovanni, Giletta y Barberis (2008) para el maní; Iglesias, Thornton, Rocco, Saravia y Paggi (2006) para la industria agroalimentaria láctea; Alba, Bedascarrasbure y García Álvarez-Coque (2008) para el clúster apícola; y González, Tedesco y Sastre (2016) para un incipiente clúster olivícola en el sudoeste de la provincia de Buenos Aires.

Los estudios sobre desempeño e impacto de clústeres agroindustriales en el país analizan la articulación y el logro de consensos entre los diversos actores, el desarrollo de infraestructura (Banco Interamericano de Desarrollo [BID], 2013; Niembro, 2017), el acceso y la trasferencia de tecnología (Alderete, 2013), la mejora de los sistemas de comercialización y aspectos normativos y regulatorios (Kataishi, Romano y Valle, 2017). En actividades enfocadas en productos transables, los estudios se concentran en el análisis de la producción, innovación y exportación (Alderete, 2013; BID, 2013; Bongiovanni, Giletta y Barberis, 2008). Existe una extensa batería de estudios sobre sectores productores de alimentos desde enfoques metodológicos diferentes al de clúster que no se referencian en este trabajo.

En 2009, unos productores de frutos secos de la región Valle Medio de la provincia de Río Negro decidieron agruparse con el fin de fomentar y promover el desarrollo de la actividad. A partir de esa iniciativa y por solicitud del gobierno provincial, el Programa de Servicios Agrícolas Provinciales (PROSAP) abordó la asistencia técnica en un proceso de trabajo participativo que concluyó con la generación y el seguimiento del plan estratégico de una asociación civil que engloba a la mayor parte de los productores e instituciones intermedias, educativas y gubernamentales con interés en la rama productiva de nueces, almendras, castañas y otros frutos secos. Habiendo trascurrido cinco años de proyectos conjuntos, cabe preguntarse sobre los resultados.

El valor del presente estudio radica en que cubre en parte la escasez de información disponible sobre una novel rama productiva que surgió en una región 
geográfica identificada con la producción de pomáceas, aunque con serias dificultades de supervivencia. El propósito del trabajo es ofrecer una evaluación exploratoria del impacto del incipiente clúster y orientar los cambios en la gestión actual de éste para que pueda lograr sus objetivos a largo plazo. Al mismo tiempo, el trabajo pretende servir de punto de referencia para el abordaje de clústeres incipientes en el sector de productores de alimentos. El artículo se centra en dos aspectos del desempeño. Éstos son el aprovechamiento de los canales de información, de fuentes de financiamiento y de algunas variables cuantitativas de impacto económico.

En la segunda sección se expone la metodología utilizada en la evaluación, en la tercera se sintetiza la evolución del clúster de frutos secos de la Norpatagonia argentina, después se exponen los resultados de la evaluación y en la quinta sección se presentan las consideraciones finales.

\section{Metodología}

Conceptualización

Se entiende por clúster una concentración geográfica de un conjunto de empresas e instituciones públicas y no gubernamentales (Palau y Napolitano, 2011; Porter, Furman y Stern, 2000; Ramos, 1998; Vera Garnica, 2009) que mantienen relaciones horizontales, verticales y multilaterales (Palau y Napolitano, 2011; Ramos, 1998). Es una red en la que los productores compiten, pero también cooperan (Porter, Furman y Stern, 2000) para que la suma global sea mayor a la suma de las partes (Palau y Napolitano, 2011).

Un clúster agroindustrial puede ser considerado como una concentración de productores e instituciones que están involucrados en el sector agrícola o alimentario, interconectados entre sí y que construyen una red de valor formal o informal, con el fin de lograr superar retos y perseguir oportunidades comunes (Gálvez-Nogales, 2010). Kataishi, Romano y Valle (2017) agregan que los actores, una vez que se reconocen como tales, comienzan a trabajar en colaboración para generar sinergias y feedbacks que potencian la productividad.

La particularidad del clúster alimentario radica en que su centralidad es el conjunto de productores, a partir de quienes se desarrolla la red de relaciones que contribuye a la generación de valor (Lozano Uvario y Méndez Guardado, 2015). Las dinámicas de competencia y cooperación que se establecen en el seno de esta concentración geográfica agroalimentaria, integrada en su mayoría por actores y empresas de pequeña o mediana dimensión, ayudan a explicar sus niveles de competitividad. Así, las dinámicas de rivalidad que se generan entre empresas del propio sector, definen un contexto de permanente competencia, lo cual incentiva la innovación, la calidad y el desarrollo de servicios nuevos y avanzados (Martínez-Paz, Martínez-Carrasco y Dios Palomares, 2005).

La conceptualización de clúster agroindustrial supera los enfoques de las cadenas de valor y de redes, poniendo el énfasis en las relaciones que se establecen entre la cadena de valor y las instituciones gubernamentales, empresariales, científicas y tecnológicas interesadas en el desarrollo de los sectores 
involucrados (Lozano Uvario y Méndez Guardado, 2015). El marco de análisis económico se apoya en el concepto de economías externas, en la observación de las acciones conjuntas para la búsqueda de un dinámico nivel de eficiencia colectiva (Enright y Ffowcs-Williams, 2000; Palau y Napolitano, 2011; Ramos, 1998; Schmitz y Nadvi, 1997) y en la innovación como medio para alcanzar y mantener ventajas competitivas (Ramos, 1998; Vera Garnica, 2009).

El interés por las iniciativas clúster, que buscan mejorar la competitividad de los actores y mejorar el desarrollo en los territorios, ha generado la necesidad de evaluaciones de desempeño e impacto. La evaluación permite obtener, a partir de fuentes fidedignas, la información cuali-cuantitativa necesaria para alcanzar mejoras de eficiencia en la selección de programas y políticas, y para adaptar su planificación y ejecución al tipo de actores sociales, a sus necesidades, al tipo de interrelaciones y al territorio específico.

En este marco, la evaluación se define como exámenes periódicos y objetivos de un programa en curso o completado; es el proceso a partir del cual surgen juicios fundados en mediciones sobre los objetivos comprometidos en un programa (Vera Garnica, 2011). Según Gertler, Martínez, Premand, Rawlings y Vermeersch (2011), incluye tres conjuntos de preguntas: 1) preguntas descriptivas: internamente describen procesos, condiciones y relaciones organizacionales; 2) normativas: evalúan lo que está ocurriendo y lo comparan con lo que debería ocurrir; 3 ) sobre causas y efectos: examinan resultados y determinan el grado de responsabilidad del programa. Las evaluaciones de impacto son un caso particular de estas últimas, en las que se utiliza el escenario contrafactual como contraste.

Los clústeres no buscan generar impacto directo en el desempeño de las empresas. Son los efectos secundarios los que van a generar mayor eficiencia, por lo que los evaluadores deben analizar los efectos intermedios que se dan a mediano plazo. Los impactos generados en la etapa denominada por lo común de formulación, están relacionados con el fortalecimiento del entramado institucional público, privado y técnico-educativo (Alemán Baires, 2004; Becerra, Serna y Naranjo, 2011; Enright y Ffwocs-Williams, 2000; Fuchs y Yoguel, 2003; Kataishi, Romano y Valle, 2017; Maffioli, Pietrobelli y Stucchi, 2016).

Martínez-Carrasco Pleite y Martínez Paz (2012) destacan elementos centrales en el fomento de las dinámicas de competencia e innovación que plantean las ventajas de los clústeres: presencia de grandes empresas, orientación exportadora, vinculación directa con mercados de destino, heterogeneidad de los actores y calidad de las interrelaciones entre los integrantes del clúster.

A partir del intercambio entre actores localizados con cercanía geográfica, se produce una sinergia que a menudo se traduce en acuerdos, factor esencial a la hora de pensar en la sustentabilidad de los proyectos de articulación (Costamagna y Rossi, 2015; González Gómez, 2011; Kataishi Romano y Valle, 2017). En esta primera etapa, se logra la generación de un lenguaje común, el consenso sobre el diagnóstico, así como una visión compartida que, plasmada en un plan estratégico, permite guiar las acciones cotidianas y generar un círculo virtuoso (Tedesco, 2009; Vera Díaz, 2010). Rivera-León y Kataishi (2010) mencionan que la interacción promueve el aprendizaje de los actores y que la colaboración es 
capaz de generar sinergias que afectan de manera positiva el entramado productivo local.

A mediano plazo, como resultado del funcionamiento, se destacan el acceso a mayor capacitación y asesoramiento (Enright y Ffwocs-Williams, 2000; Pietrobelli y Rabelloti, 2006; Tedesco, 2009), el funcionamiento y formulación de normativas, así como la trasparencia en procesos productivos y comerciales (Grueso, Merlín, Gómez y Quintero, 2009; Ramos, 1998), la generación de economías de escala y el aumento de productividad (Maffioli, Pietrobelli y Stucchi, 2016), la creación de nuevas empresas (Organización para la Cooperación y el Desarrollo Económico [OECD], 2005; Vera Garnica, 2009), el acceso a nuevos mercados (Alemán Baires, 2009; Ramos, 1998) y un mayor grado de innovación (Becerra, Serna y Naranjo, 2013; Dini, Ferraro y Gasaly, 2007), entre otros beneficios.

Sin embargo, diversos autores plantean que la introducción de iniciativas clúster en países en vías de desarrollo no tiene en cuenta que son extrapolaciones de marcos para programas en países desarrollados o en sectores distintos (Palau y Napolitano, 2011). A las iniciativas clúster las consideran descontextualizadoras, ahistóricas y acríticas de los conceptos que la conforman, y señalan que su uso y abuso contribuyeron en América Latina a una borrosidad conceptual, lo cual, sumado a un tratamiento empírico laxo, debilita la política pública.

En Argentina, los factores condicionantes en la implementación y que merecen tenerse en cuenta en el momento de evaluar, están relacionados con los cambios de contexto político e institucional, el limitado acceso a instrumentos de financiación y demoras en procedimientos, la participación de diferentes organismos e instituciones con lógicas y culturas diversas - algunos con dependencias jurisdiccionales distintas-, la elevada segmentación y heterogeneidad de agentes al interior de las cadenas y la fragilidad de algunas instituciones públicas y privadas, entre otros problemas (Alemán Baires, 2009; Ferraro y Stumpo, 2010; Palau y Napolitano, 2011).

Fuentes y evaluación

El clúster de frutos secos se ubica en Alto Valle, Valle Medio y Valle Inferior del río Negro en la Patagonia argentina (Norpatagonia), pertenecientes en términos jurisdiccionales a las provincias de Río Negro y de Neuquén. La actividad tradicional regional está orientada a la producción de peras y manzanas, que concentra $85 \%$ de la producción nacional de estas pomáceas y sitúa a Argentina como el primer exportador del hemisferio sur de peras y quinto de manzanas (Avellá, Landriscini y Preiss, 2018).

La explotación de frutos secos se extiende en el territorio con una distancia máxima de 600 kilómetros $(\mathrm{km})$ entre sus extremos y cuenta con un área de 1945 hectáreas (ha) implantadas. Del total de la superficie, 1448.5 ha se encuentran implantadas con nogales, cuya producción se estima en 2395.3 toneladas, y la implantación de avellanas ronda las 496.66 ha, con una producción estimada de 2814.6 toneladas. Los establecimientos de los productores de nogales, avellanas y mixtos ascienden a 162 (Consejo Federal de Frutos Secos, 2017). 
Figura 1. Distribución de establecimientos productores de frutos secos, por especie, 2017

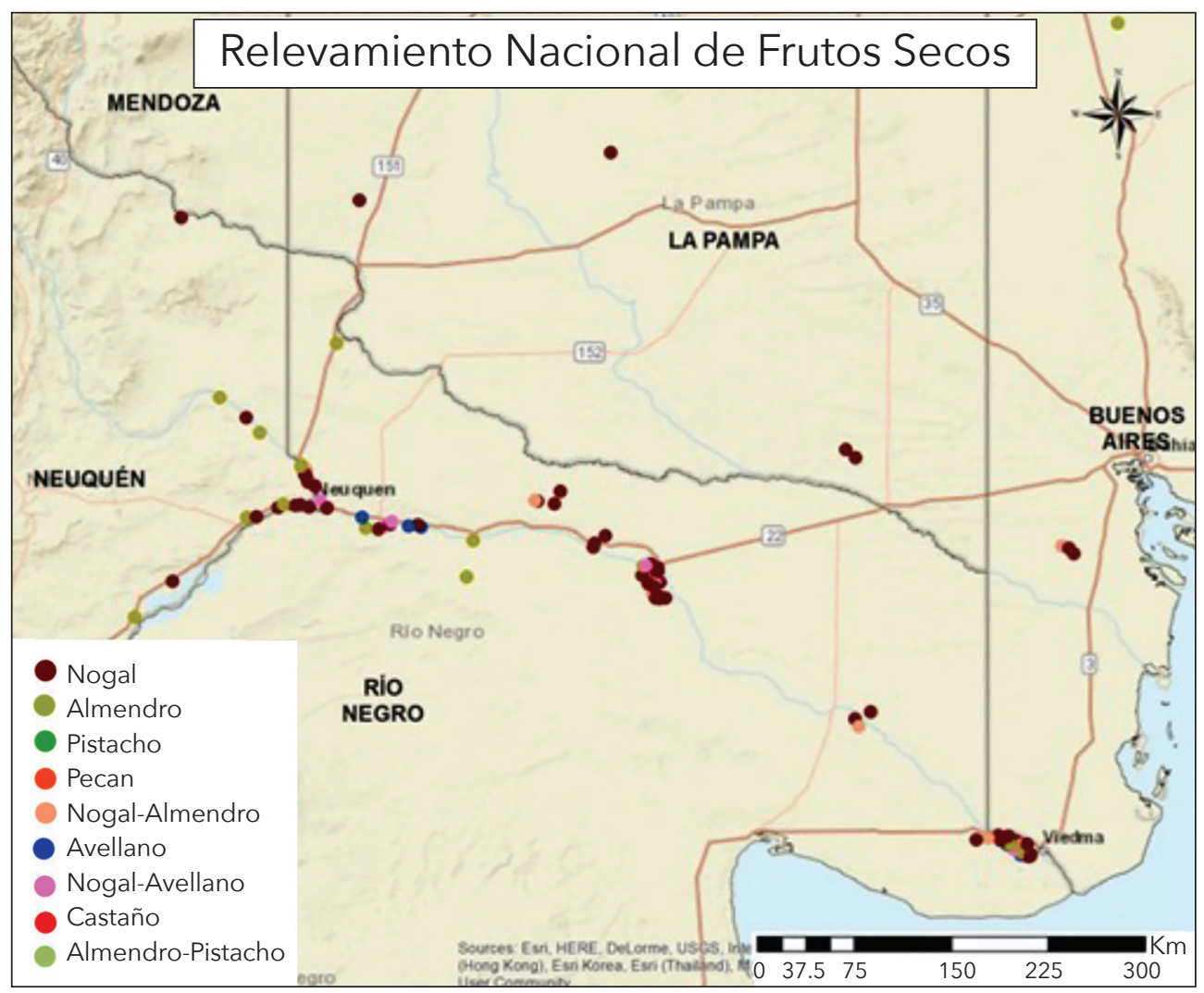

Fuente: Mapa 8.5 del Informe final del Relevamiento Nacional de Frutos Secos (Consejo Federal de Frutos Secos, 2017, p. 69).

En la figura 1 se aprecia la distribución geográfica de los productores en la región de la Norpatagonia argentina, considerando el tipo de fruto seco que se produce en cada caso.

Existen tres estratos de productores. El primero corresponde a productores diversificados que destinan superficies menores a 5 ha, realizan las actividades con la familia y contratan trabajadores transitorios de forma eventual. El segundo corresponde a establecimientos de entre 5 y 20 ha que se encuentran en proceso de reconversión desde la horticultura hacia los frutos secos. El tercero corresponde a superficies de entre 20 y 40 ha pertenecientes a empresarios que buscan alternativas de inversión. Poseen mayor infraestructura y tecnología poscosecha (PROSAP, 2010).

Se observan diferencias en los perfiles de los productores los cuales guardan relación con las zonas de explotación. Los del Valle Inferior y Alto Valle de Río Negro y Neuquén poseen un perfil de tipo empresario y establecimientos de mayor tamaño que los de los productores del Valle Medio. Este perfil se correspon- 
de con personerías jurídicas avanzadas, como sociedades de responsabilidad limitada (S. R. L.) y sociedades anónimas (S. A.), y con labores profesionales en los sectores del petróleo y de servicios, entre otros, como actividad económica principal. También componen este grupo los productores integrados, es decir, productores que realizan todas las actividades de poscosecha y agregado de valor y cuya comercialización de frutos secos representa su actividad económica principal.

En el presente trabajo, el objeto de estudio ha sido la Asociación Civil del Clúster de Frutos Secos de la Norpatagonia, institución intermedia que involucra a la mayor parte de los productores e instituciones que desarrollan actividades vinculadas de manera directa o indirecta a la producción, trasformación y comercialización de nueces y avellanas.

La evaluación tuvo carácter retrospectivo. La actividad productiva se origina con la siembra de los primeros nogales con fines comerciales en la década de 1990. Sin embargo, la ventana temporal del estudio comprendió diez años, entre 2009 y 2018, es decir, desde la creación de la asociación civil que representa al clúster hasta la actualidad.

La evaluación se realizó siguiendo la clasificación de Gertler et al. (2011). Para los componentes descriptivo y normativo, se consultaron fuentes de información primarias y secundarias. Se realizó una revisión de los documentos internos, actas e informes del clúster, además de antecedentes bibliográficos sobre la producción de frutos secos en la región. En particular, se utilizó la descripción del clúster que ofrecen Villegas, Miñón, Di Nardo y Carusso (2014) y el Plan de Mejora Competitiva (PMC) de 2010.

Los datos recabados en esas investigaciones fueron complementados con información suministrada por cuatro agentes calificados a partir de entrevistas semiestructuradas en profundidad, dos de los cuales participaron desde el inicio en las actividades de la asociación: un excoordinador del clúster y un exfacilitador metodológico del programa Iniciativas de Desarrollo de Clústeres de la Unidad para el Cambio Rural del Ministerio de Agroindustria de la Nación Argentina. Los dos restantes representaron a entidades de trasferencia tecnológica en la región: la Estación Experimental Agropecuaria de Valle Medio del Instituto Nacional de Tecnología Agropecuaria (INTA EEA Valle Medio) y la Secretaría de Vinculación y Transferencia Tecnológica de la Universidad Nacional del Comahue.

Para el componente de evaluación de causa y efecto, se realizó una segunda ronda de entrevistas semiestructuradas a 10 productores de las distintas regiones que conforman el clúster. La elección de los productores para las entrevistas se hizo a partir de la identificación de los sujetos reconocidos como importantes por la mayoría de los agentes calificados, tarea que fue encomendada a la actual coordinadora de la asociación civil que los reúne. Esa información fue luego confirmada con las entrevistas, asegurando el cumplimiento de los criterios de representatividad y de diversidad de perspectivas.

Tal como señalan Gertler et al. (2011), y debido al carácter retrospectivo de la evaluación, la construcción del escenario contrafactual representó un problema. Una opción podría haber sido considerar para tal fin la evolución de los 
productores que no participaron de manera formal. Sin embargo, la fortaleza de cualquier clúster radica en las conexiones, no necesariamente formales, que facilitan la difusión de información y que generan externalidades en los productores que no están asociados y en otros sectores productivos. Incluso podrían presentarse comportamientos del tipo free-rider. Por consiguiente, existe una dificultad intrínseca al proceso de evaluación de clúster centrado sólo en el propio territorio.

Siendo éste un sector productor novel con respecto a otras regiones argentinas, tampoco se cuenta con un contrafactual apropiado en otros territorios dentro del mismo país. Por otro lado, la utilización de clústeres productores noveles de otros países como contrafactual enfrentaría problemas de selección relacionados con diferencias idiosincráticas, normativas y económicas.

Por ende, ante esta limitación, se optó por tomar la información de dos momentos del tiempo correspondientes al mismo individuo. El supuesto implícito en la comparación entre antes y después es que, de no haber existido el clúster, hubieran sido nulas las variaciones en los indicadores elegidos para la evaluación o hubieran tomado una tendencia natural de crecimiento -por ejemplo, se hubiera observado sólo un crecimiento natural de la productividad en términos de kilogramos por planta en función del clima, suelo y enfermedades, entre otras cosas-. Como se verá más adelante, se lidió con el riesgo de caer en un contrafactual falso con una selección ajustada de los indicadores y haciendo las salvedades que correspondieran. Por estos motivos, el ejercicio representa una aproximación a la evaluación de impacto y no una evaluación en términos estrictos.

Podría hacerse una evaluación con un contrafactual más apropiado tras un periodo más largo comparando el desenvolvimiento de productores que participaron de forma activa en el clúster con los resultados obtenidos por productores que, habiendo iniciado su actividad de manera simultánea con los primeros, tuvieron un rol secundario o marginal a lo largo de la ventana temporal de la evaluación. Dado que el periodo trascurrido aún no es suficientemente largo, se ha optado por aquella aproximación.

Las entrevistas se enfocaron en el probable impacto en el desempeño y el territorio a partir de cuatro ejes: económico-productivo, político e institucional, social y cultural y ambiental. Para cada uno se recolectó información para un conjunto amplio de variables, algunas de las cuales sirvieron para describir el clúster, sus conexiones y su evolución, y otras para la evaluación. La tabla 1 muestra esta información y las referencias bibliográficas que se utilizaron para su justificación.

La estructura de las entrevistas se constituyó de la descripción de los antecedentes de los productores, la identificación del comienzo en la actividad, la forma en que toman sus decisiones y la evolución productiva y comercial. Se consultó, además, sobre la red de vínculos dentro y fuera del clúster. En una segunda parte, se avanzó en el análisis de las políticas vinculadas al sector y al clúster, para luego pasar a una serie de preguntas sobre formación y capacitación específica, hitos en el desarrollo del emprendimiento y puntos críticos en la actividad. La tercera parte de la entrevista se enfocó en el desempeño del 
clúster, los beneficios que se obtuvieron a partir de su creación en materia de financiamiento, desarrollo tecnológico, inversiones, posicionamiento, acciones colectivas.

Este artículo se enfoca sólo en la evaluación cuantitativa de los efectos en un subgrupo de variables definido por la disponibilidad de información ex-ante y ex-post: la evolución de superficie plantada con frutos secos, la formación de recursos humanos, la productividad, las inversiones realizadas y las experiencias de exportación.

Tabla 1. Ejes de evaluación de impacto en clústeres agroindustriales

\begin{tabular}{|c|c|}
\hline Ejes del desarrollo territorial & Variables de evaluación \\
\hline Económico-productivo & $\begin{array}{r}\text { Nivel de producción; productividad; generación } \\
\text { de empleo; valor agregado. }\end{array}$ \\
\hline Político e institucional & $\begin{array}{r}\text { Gasto público hacia el sector; inversiones del sector } \\
\text { privado y nivel de apoyo gubernamental } \\
\text { (capacidad para generar empleo); existencia } \\
\text { de políticas públicas para el sector; acceso } \\
\text { a la información; apoyo institucional. }\end{array}$ \\
\hline Social y cultural & $\begin{array}{c}\text { Formación de capital humano; grado } \\
\text { de cooperación; nivel de capacitación; } \\
\text { educación especializada y específica. }\end{array}$ \\
\hline Ambiental & Uso de energías consumidas; uso del suelo; \\
& tratamiento de residuos. \\
\hline
\end{tabular}

Fuente: elaboración propia a partir de Meyer-Stamir y Harmes-Liedtke (2005), Tedesco (2009), Vera Díaz (2010), Perdomo y Malaver (2013) y Pomareda y Arias (2007).

\section{Asociación Civil del Clúster de Frutos Secos de la Norpatagonia}

En 1999 se realizó la primera actividad de extensión destinada a un grupo de productores de frutos secos de Valle Medio, promovida por la Fundación para el Desarrollo de la Norpatagonia y el gobierno de la provincia de Río Negro. La propuesta consistió en participar en un congreso de nogalicultura en la provincia argentina de Catamarca. Quienes viajaron fueron los primeros en plantar nogales con fines comerciales en la Norpatagonia durante los primeros años de la década de 1990. Los productores eligieron la producción de frutos secos por ser una actividad redituable, fácil de acondicionar, trasportar y vender, comparada con lo que sucedía (sucede) con las peras y manzanas. Por esa época existió, además, una serie de instrumentos crediticios promovidos por el gobierno provincial. Aún no se observaban vínculos entre estos productores. Sin embargo, fue a partir de aquella experiencia que comenzaron a asociarse (Lattuada, 
2014). Ante la carencia de recursos humanos especializados en la región, los primeros productores recibieron asesoramiento del Instituto Nacional de Tecnología Agropecuaria (INTA) a través de la Agencia de Extensión Rural Tupungato (Provincia de Mendoza) y del Centro de Investigación Rayentué del Instituto de Investigaciones Agropecuarias del Ministerio de Agricultura de Chile.

En 2002 se activó una chacra experimental dispuesta por el gobierno de la provincia de Río Negro para que fuera utilizada por los productores. También, con apoyo del gobierno provincial y mediante un préstamo del Banco Interamericano de Desarrollo (BID), en 2003 se financiaron dos iniciativas: una productiva en Alto Valle y otra tecnológica en la zona andina. Lattuada (2014) destaca los antecedentes institucionales del clúster a escalas local, provincial y nacional, tales como grupos de Cambio Rural del INTA, las cooperativas y cámaras de productores, las acciones de apoyo del Ministerio de Agricultura, Ganadería y Pesca de la Provincia de Río Negro, entre otros.

\section{Tabla 2. Objetivos estratégicos del Plan de Mejoramiento Comercial} (PMC)

\begin{tabular}{|c|c|}
\hline Sector de la cadena & Objetivos estratégicos \\
\hline Sector primario & $\begin{array}{l}\text { - Consolidar y difundir las pautas tecnológicas para la } \\
\text { - Aroducción de nueces y avellanas, acordes con la región. } \\
\text { - } \text { necesidades de las empresas. } \\
\text { - Promover intercambio de tecnología entre regiones. } \\
\text { - Homogeneizar la calidad de los productos obtenidos } \\
\text { y minimizar pérdidas. }\end{array}$ \\
\hline $\begin{array}{l}\text { Acondicionamiento } \\
\text { e industrialización }\end{array}$ & $\begin{array}{l}\text { - Ampliar la infraestructura de acondicionamiento de forma } \\
\text { tal que acompañe el crecimiento de la producción. } \\
\text { - Promover innovaciones para obtener productos diferenciados. }\end{array}$ \\
\hline Comercialización & $\begin{array}{l}\text { - Contar con información actualizada sobre oportunidades } \\
\text { - Comerciales y evolución del mercado. } \\
\text { - Conocer los distintos canales de comercialización en mercados } \\
\text { internos y externos y los perfiles de consumidor. Aumentar la } \\
\text { presencia como región patagónica en el mercado interno. } \\
\text { - Conseguir capacidad de abastecer con productos adecuados } \\
\text { - Adquirir capacidades internas de las empresas para lograr } \\
\text { - exportar a mercados potenciales. } \\
\text { - Desarrollar relaciones comerciales en países próximos. } \\
\text { - Explar las oportunidades del mercado de contra-estación. }\end{array}$ \\
\hline Recursos humanos & $\begin{array}{l}\text { - Contar con recursos humanos capacitados para las prácticas } \\
\text { culturales (personal y mandos medios) y asesoramiento técnico } \\
\text { y comercial. }\end{array}$ \\
\hline Entorno & $\begin{array}{l}\text { - Consolidar capacidades para la gerencia de acciones } \\
\text { estratégicas acordadas. } \\
\text { - Generar mecanismos de vinculación entre diferentes } \\
\text { eslabones de la cadena e instituciones del entorno. }\end{array}$ \\
\hline
\end{tabular}

Fuente: elaboración propia con base en PROSAP (2010). 
En 2009, el gobierno provincial y el PROSAP propusieron la conformación de la asociación civil a los productores involucrados en esta actividad. El PROSAP tomó a su cargo el diseño y seguimiento de una metodología de trabajo participativo que involucró a la Agencia de Desarrollo Rionegrino (CREAR), al Instituto de Desarrollo del Valle Inferior (IDEVI), al Ministerio de la Producción de la Provincia de Río Negro, a la Universidad Nacional de Río Negro, a la Universidad Nacional del Comahue, al INTA y a las asociaciones de productores de Valle Medio y Valle Inferior. Así, la conformación del clúster respondió a la triple hélice marcada por Etzkowitz y Leydesdorff (1997).

En 15 meses de trabajo se definió el Plan de Mejora Competitiva (PMC) de la nueva Asociación del Clúster de Frutos Secos de Río Negro, tras lo cual dio comienzo la segunda etapa del proceso, que consistió en la ejecución de los proyectos definidos con financiamiento del BID a través del PROSAP (Tagliani, 2016).

La tabla 2 especifica los objetivos estratégicos definidos en el PMC y queda señalada con claridad la relevancia que para los involucrados tiene la trasferencia de información.

En 2013 se conformó una nueva acta constitutiva con la incorporación de los productores de la zona de Alto Valle de Río Negro y Neuquén. La asociación cambió su denominación por el nombre actual: Asociación Civil del Clúster de Frutos Secos de la Norpatagonia. La asociación avanzó, de esa manera, en el fortalecimiento de la coordinación de la cadena y se expandió en el territorio. La figura 2 muestra la composición definitiva de la Asociación.

Figura 2. Asociación Civil del Clúster de Frutos Secos de la Norpatagonia

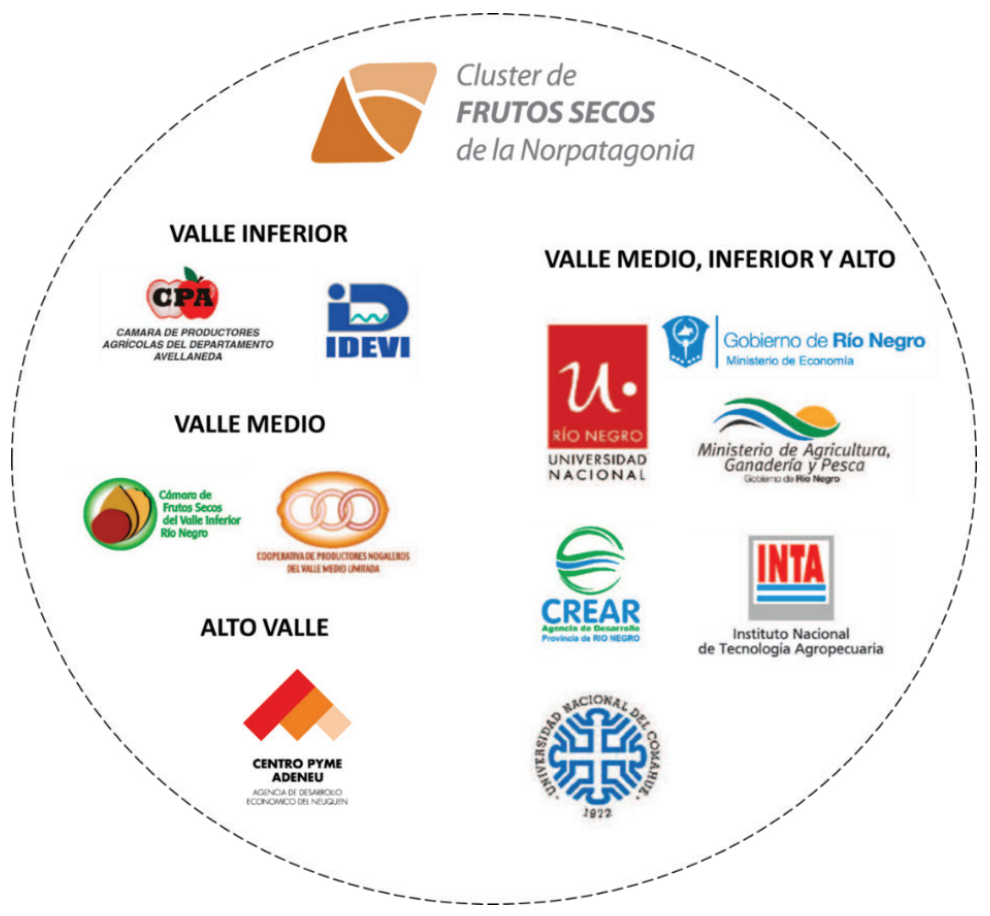

Fuente: elaboración propia. 
La asociación fue generando vínculos con otras instituciones de la región, entre ellas el Centro de Especialización en Asuntos Económicos Regionales (CEAER), el Instituto Nacional de Tecnología Industrial (INTI), la empresa Ferrero Corilicola, S. A. del Grupo Ferrero, el Clúster Empresarial CIDETER de la Maquinaria Agrícola (CECMA), el Centro de Investigación y Extensión Forestal Andino Patagónico (CIEFAP) e instituciones nacionales, como la Unidad para el Cambio Rural (UCAR) del Ministerio de Agricultura de la Nación y el Ministerio de Ciencia y Tecnología de la Nación (Asociación Civil del Clúster de Frutos Secos de la Norpatagonia, 2016).

Otra extensión geográfica del clúster se alcanzó en 2016, cuando la asociación participó en la conformación del Consejo Federal de Frutos Secos con instituciones intermedias de otras regiones del país, entre ellas, el Clúster Nogalero de La Rioja, el Clúster de Frutos Secos de Mendoza y el Clúster de la Nuez Pecán de Entre Ríos (Consejo Federal de Frutos Secos, 2016). Entre las acciones iniciales del Consejo, se consensuaron dos proyectos relacionados con la generación de información en el sector de frutos secos y la creación de condiciones para la incorporación de la mecanización en la cadena de valor.

Figura 3. Cadena de valor de frutos secos en Norpatagonia

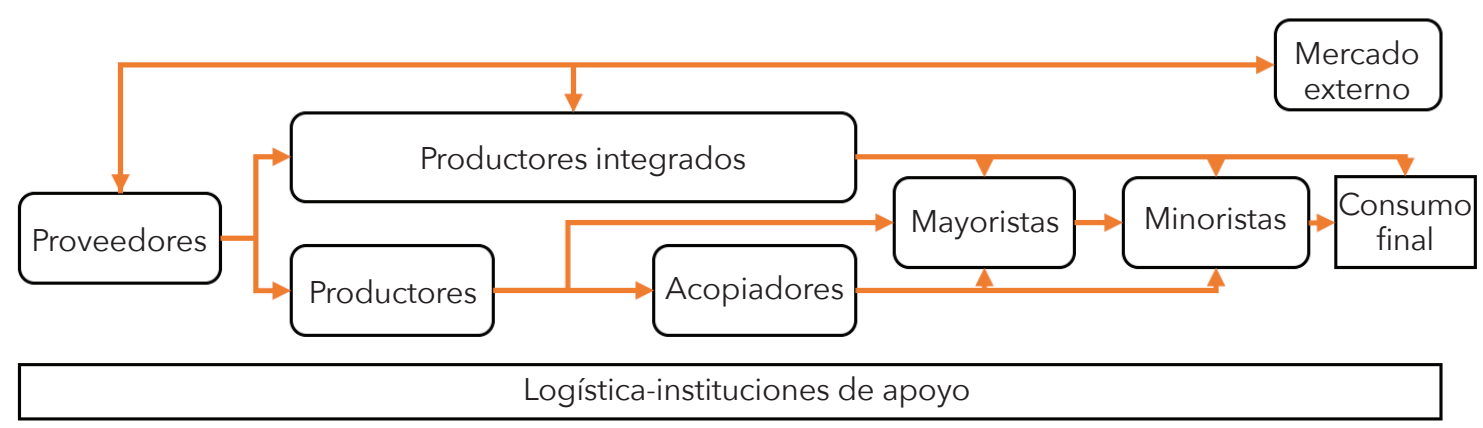

Nota: La relación entre el mercado externo y los proveedores, y entre aquél y los productores integrados es bidireccional debido a que son los mismos agentes los que exportan e importan el producto.

Fuente: elaboración propia con base en Villegas (2014) e información suministrada por los participantes.

En la figura 3 se exponen los participantes de la cadena de valor de frutos secos. Según datos de 2014, el consumo per cápita de nuez en Argentina fue de 220 gramos por año y de avellana, 7.14 gramos/año. Sin embargo, la demanda en la región norpatagónica es la más alta del país. Sólo dos productores entre los entrevistados comercializan su producción fuera de esta región. El consumo regional es estacional: mientras que la demanda aumenta en invierno en la zona andina, incrementa en verano en la zona más próxima a la costa atlántica. 
El producto inicia su recorrido en la etapa de poscosecha. Ésta se caracteriza por las funciones de secado, pelado, limpieza, fraccionamiento, clasificado y, en algunos casos, envasado. El fruto seco, sin embargo, puede adquirirse con cáscara o sin ella. Según datos de 2017, la provincia de Río Negro comercializa $51 \%$ de la nuez con cáscara, mientras que la provincia de Neuquén, 73\%. La avellana es comercializada en $60 \%$ sin cáscara, y la provincia de Río Negro es la única productora en el país.

En cuanto al precio, los frutos secos con cáscara poseen un precio menor que aquéllos con mayor valor agregado, aunque sea sólo el pelado. El precio se ve afectado por el volumen y por el precio de los frutos secos con origen en otras regiones argentinas, aunque no lo es de manera significativa por productos importados. En relación con las avellanas, los volúmenes importados han superado el nivel de la producción nacional. Sin embargo, la producción regional está orientada al mercado internacional (en 2017 se exportó más de 84\%). Tampoco es significativa la competencia en el mercado doméstico con nueces importadas. Aunque el precio puede verse afectado por las oportunidades de exportaciones, esta apreciación no se encuentra verificada.

La mitad de los encuestados manifestó que desarrolla algún agregado de valor a los productos, fundamentalmente asociado con el envasado, la generación de mezclas de frutos secos, la elaboración de snacks o garapiñadas. Si bien existe una mayor conciencia de la necesidad de cumplir con las normas fiscales, bromatológicas y de empaquetado, aún se visualiza una importante informalidad en el canal directo desde el productor hacia el consumidor final. Estas ventas se realizan a través de bocas de expendio propias o utilizando redes sociales. De todas formas, son reducidas en términos del volumen total.

La distribución se compone de acopiadores regionales, intermediarios mayoristas y comercios minoristas que difieren a su vez entre sí según realicen actividades relacionadas con la trasformación del producto. Entre las principales funciones de los mayoristas, se observa el almacenamiento, el preparado del producto, el pelado y la venta al minorista. En algunos casos existe financiamiento al productor. Por lo general, los mayoristas y acopiadores están ubicados cerca de los centros de producción o de consumo. Sin embargo, también existen productores integrados que realizan la etapa poscosecha en sus propias fincas (PROSAP, 2010).

Hay mercados concentradores que se dedican al almacenaje y a la conservación del producto con cáscara, y se ubican en la cadena entre los acopiadores y los minoristas. Los mercados concentradores están en la ciudad de Neuquén en el Alto Valle del Río Negro, y en Bahía Blanca, ciudad costera de la provincia de Buenos Aires. Un hito significativo del clúster es la creación de la Planta de Acondicionamiento y Conservación de Valle Medio, en la ciudad de Luis Beltrán. En ella, los productores asociados al clúster realizan de forma conjunta las actividades de secado, clasificado y lavado, lo cual facilita el agregado de valor en forma colectiva, la certificación de los procesos y la unificación de la calidad.

En el sector minorista se encuentran las verdulerías, herboristerías, chocolaterías, heladerías, panaderías, supermercados, hoteles, restaurantes y caterings. Las chocolaterías y las heladerías son los minoristas que realizan el 
Tabla 3. Matriz de avance y aportación de los proyectos iniciales

\begin{tabular}{|c|c|c|}
\hline Proyecto & $\begin{array}{c}\text { Grado de avance } \\
\text { (inicio, en proceso, } \\
\text { avanzado) }\end{array}$ & $\begin{array}{c}\text { Aporte a los } \\
\text { objetivos del clúster } \\
\text { (menor, intermedio, } \\
\text { significativo) }\end{array}$ \\
\hline $\begin{array}{l}\text { Institucionalización del clúster: } \\
\text { conformación de la asociación civil }\end{array}$ & Avanzado & Significativo \\
\hline $\begin{array}{c}\text { Sistema de información estratégica, } \\
\text { observatorio del clúster }\end{array}$ & En proceso & Intermedio \\
\hline Desarrollo comercial, mercado externo & En proceso & Intermedio \\
\hline $\begin{array}{c}\text { Desarrollo comercial, mercado interno, } \\
\text { promoción conjunta y posicionamiento } \\
\text { de los productos del clúster en el } \\
\text { mercado interno }\end{array}$ & En proceso & Significativo \\
\hline Confección de un manual de avellanas & Avanzado & Significativo \\
\hline $\begin{array}{l}\text { Viaje de referencia a Chile con } \\
\text { productores avellaneros }\end{array}$ & Avanzado & Menor \\
\hline $\begin{array}{l}\text { Control de heladas, experimentación } \\
\text { adaptativa y adopción de métodos } \\
\text { de control por los productores }\end{array}$ & En proceso & Intermedio \\
\hline $\begin{array}{l}\text { Adaptación y aplicación de métodos } \\
\text { para control de carpocapsa }\end{array}$ & En proceso & Significativo \\
\hline Control de patógenos de suelo & En proceso & Significativo \\
\hline $\begin{array}{l}\text { Sensibilización y diagnóstico para } \\
\text { la aplicación de buenas prácticas }\end{array}$ & Inicio & Menor \\
\hline $\begin{array}{c}\text { Tecnicatura Superior en Gestión } \\
\text { Agropecuaria, Orientación Frutos Secos }\end{array}$ & Sin avance & Menor \\
\hline Plan Plurianual de Capacitación & En proceso & Significativo \\
\hline Especialización en Frutos Secos & Avanzado & Significativo \\
\hline Diplomatura en Frutos Secos & Sin avance & Menor \\
\hline $\begin{array}{l}\text { Planta colectiva de acondicionamiento } \\
\text { y empaque para nueces }\end{array}$ & Avanzado & Significativo \\
\hline $\begin{array}{c}\text { Experiencia piloto de productos } \\
\text { terminados y semielaborados a base } \\
\text { de nueces y avellanas }\end{array}$ & Avanzado & Significativo \\
\hline
\end{tabular}

Fuente: elaboración propia. 
mayor agregado de valor partiendo desde el producto pelado (Villegas, 2014). Pero los frutos secos son un producto de baja relevancia comercial para los supermercados.

A partir del proyecto Experiencia Piloto de Productos Terminados y Semielaborados a Base de Nueces y Avellanas del PMC, se llevaron a cabo diversas actividades impulsadas por la Universidad Nacional de Río Negro en materia de investigación de aceites y harinas. Además, se adquirió la maquinaria necesaria mediante el financiamiento de UCAR, con lo cual se lograron avances en la producción y la presentación de aceites. Algunos productores ya comercializan este producto a partir de esa experiencia.

Otro hito en la vida del clúster es el Centro de Servicios para el Agregado de Valor (SEPAV), proyecto que se presentó a PROSAP en 2014, se aprobó en 2015 y se concretó tres años después. Los objetivos del SEPAV están alineados con el proyecto mencionado del PMC, pero permitió dar un salto cualitativo importante en infraestructura, equipamiento y tecnología.

Para finalizar esta sección descriptiva, en la tabla 3 se enumeran los proyectos iniciales que buscaron avanzar en el cumplimiento de los objetivos del clúster, su estado actual y el aporte real en opinión de los participantes.

\section{Resultados}

En cuanto a los factores que inciden en el desempeño de los productores, el análisis se concentró en la valoración que hacen los productores sobre el flujo de información dentro del clúster y en las oportunidades de financiamiento disponible y en qué medida fueron aprovechadas.

En cuanto al primero de los temas, la responsabilidad de mantener la dinámica de trabajo con la participación de todos los actores recae en el coordinador, quien programa reuniones periódicas y las conduce para escuchar todas las inquietudes que plantean las distintas organizaciones e instituciones participantes. También propone pautas organizativas, gestiona la administración de los recursos disponibles y colabora en la obtención de recursos extraordinarios, necesarios para ejecutar los proyectos. No es quien genera la información, pero es quien facilita su trasmisión.

Con una frecuencia mensual, se reúne el equipo técnico que sigue el desarrollo de los proyectos; las decisiones son tomadas por el directorio conformado por representantes de las instituciones y de los productores. Una gestión eficiente de la información generada en estas instancias, sumada a la oferta de actividades de extensión, redundaría en beneficios económicos a mediano y largo plazos para los productores.

En efecto, los productores entrevistados subrayaron la importancia del acceso a información actualizada a través de jornadas y ensayos con técnicos especializados. Las reuniones periódicas y las asambleas propias de la gestión de la asociación fueron señaladas como espacios donde se discuten prácticas, se plantean problemas y se adaptan objetivos, entre otros aspectos relevantes 
de funcionamiento e interpretación colectiva del clúster. Incluso algunos productores opinan que lo más favorable de participar en la asociación surge en los encuentros formales e informales con técnicos y visitantes de otras regiones productoras de frutos secos del país. De los entrevistados, $70 \%$ manifestó participar con suficiente frecuencia de todas estas actividades.

Sin embargo, 30\% sigue percibiendo alto el costo de oportunidad de asistir a las reuniones o de participar en la gestión. Las valoraciones que los productores realizan sobre los beneficios económicos obtenidos a partir de sus actividades cotidianas que no están vinculadas a los frutos secos superan los beneficios esperados por destinar tiempo a las actividades de la asociación. Otros observan una deficiencia en la gestión de la información y se la atribuyen a los representantes de los organismos públicos, cuya representatividad es discutible o su permanencia en el cargo es baja.

El 40\% coincide en la necesidad de concretar una mayor cantidad de acciones colectivas para avanzar en la integración de los productores del Alto Valle, quienes se sumaron en una etapa posterior a los del Valle Medio y del Valle Inferior.

Si bien está generalizada la valoración positiva con respecto a la información disponible, la calidad del flujo de ésta es deficiente. A pesar de haber logrado avances significativos en cuanto a periodicidad y relevancia de los contenidos, los productores consideran que el tiempo dedicado aún no se ve compensado con un ingreso económico atribuible de manera directa. Esto puede deberse a una prolongada extensión de las actividades, a los temas elegidos o a la metodología de trabajo utilizada en las reuniones.

Un hecho relevante para cambiar la percepción es la conveniente comunicación de los costos y los beneficios económicos asociados con las problemáticas tratadas. Por ejemplo, es posible que los productores perciban muy positivo un curso sobre los efectos del Ectomyelois ceratoniae en la productividad del nogal y que no lo hagan en igual grado con un curso sobre certificación de origen, aun cuando la diferencia de precios entre un producto a granel y otro con certificación sea significativa en el mercado externo. La diferencia en la percepción no se explicaría por la falta de interés, debido a que los productores saben que el rédito económico existe tanto en la erradicación de una plaga como en la homogeneización de la calidad del producto asociada con la certificación. La diferencia radica en el horizonte temporal que los productores asocian con cada uno de los resultados: mientras que las mejoras en la productividad se asocian con incrementos en los ingresos de la próxima temporada, los beneficios de la certificación se asocian con un proceso de larga duración, dificultades técnicas y costos relacionados con el control de procesos. En ambos casos, los resultados en la rentabilidad son probables, pero la sensación de control sobre esos resultados es mayor en el primer caso.

En cuanto al financiamiento, la asociación abrió el acceso a un conjunto de proyectos colectivos que no se hubieran logrado financiar de forma particular. Esta afirmación fue reiterada en $\mathbf{8 0 \%}$ de las entrevistas. La personería jurídica 
permitió que se accediera a mejores opciones de financiamiento, en términos de montos y tasas, y que los productores intentaran avanzar en un proceso de auto-sostenibilidad.

Los recursos aportados por el Estado a través de diferentes instituciones o por otras instituciones a través del Estado tuvieron el fin estratégico de apalancar la captación de recursos provenientes de otras fuentes para mejorar la competitividad regional. El PMC y la Planta de Acondicionamiento y Conservación de Valle Medio fueron posibles a partir de fondos provistos por el BID, aunque también aportaron los organismos públicos y los productores a través de las instituciones intermedias (Asociación Civil del Clúster de Frutos Secos de Norpatagonia, 2016; Tagliani, 2016).

Para formalizar los aportes de contraparte, los productores beneficiarios debieron reactivar y actualizar una cooperativa local, lo cual requirió el aporte de recursos propios, además de tiempo y capacidades. La asociación recibió a través del PROSAP un monto aproximado, a precios corrientes, de 600000 dólares $^{1}$ en 2011, pero no puso en marcha sino hasta 2013 proyectos por un monto aproximado de 1700000 dólares estadounidenses (Asociación Civil del Clúster de Frutos Secos de Norpatagonia, 2016). ${ }^{2}$

Cabe aclarar que todos los proyectos formulados y ejecutados por la asociación son colectivos; es decir, no existe un agente particular que haya sido beneficiario, sino que corresponde al colectivo de un sector o actividad (PROSAP, 2010; UCAR, 2014). Sin embargo, la asociación ha permitido generar vinculaciones entre instituciones, organismos públicos y agentes del sector privado. Mediante éstas, ha logrado el acceso a fuentes de financiamiento directas para los productores y se han complementado los proyectos de índole colectiva con las necesidades particulares. De los productores entrevistados, $80 \%$ ha logrado créditos de organismos provinciales (por ejemplo, Río Negro Fiduciaria) o aportes no reembolsables a través del PROSAP. Para tener acceso a un reintegro de $40 \%$ del monto total invertido, los beneficiarios debieron presentar un proyecto coherente con los objetivos estratégicos de la asociación. Entre 2013 y 2018, 63 productores hicieron uso de este instrumento.

Sin embargo, la percepción de $90 \%$ de los entrevistados es que su aporte financiero ha sido escaso, más aún si se lo compara con los fondos aportados por instituciones y organismos públicos. En 40\% de las entrevistas realizadas a productores de Valle Medio y Alto Valle se pone de manifiesto que la falta de inversiones de índole privada ha sido una limitante para el desarrollo de los proyectos colectivos. Incluso la falta de financiamiento ha afectado la coordinación. Los honorarios del coordinador fueron aportados por la UCAR hasta la finalización del PMC. Luego la figura de coordinador fue cubierta por una per-

1 En este artículo se refiere siempre a dólares estadounidenses.

2 Los valores fueron convertidos a dólares corrientes a un tipo de cambio igual a 4.304 pesos argentinos por dólar (30 de diciembre de 2011) para el valor correspondiente a 2011, y utilizando el promedio entre aquél y 6.521 pesos argentinos por dólar (30 de diciembre de 2013) para el monto correspondiente al período consignado. Para los siguientes valores mencionados en el texto, se utilizó el mismo mecanismo de conversión. Tipo de cambio disponible en https://www.bcra.gob.ar/ PublicacionesEstadisticas/Cotizaciones_por_fecha.asp (último acceso: 18 de agosto de 2020). 
sona con carga horaria parcial y ad honorem. Ese cambio en el gerenciamiento activo llevó, según la consideración de $60 \%$ de los entrevistados, a una disminución de las actividades de trasferencia de los proyectos abordados, así como a la pérdida de oportunidades comerciales.

Para aproximar una evaluación de la asociación en el territorio, se observaron los efectos intermedios a partir de los cambios en la superficie implantada, en el rendimiento medido como el total producido en relación con ésta, las inversiones en capital físico y humano y la experiencia exportadora. La figura 4 sintetiza la información. Es posible observar cómo los efectos intermedios provocados por las actividades y proyectos del clúster crearon un entorno favorable al incremento de las cinco variables consideradas.

Cuando se conformó la asociación, la superficie implantada con nogales y avellanos en Río Negro era de 1170 ha (PROSAP, 2010). Este valor corresponde sólo a Valle Medio y Valle Inferior, ya que Alto Valle de Río Negro y Neuquén todavía no formaban parte de la asociación. La superficie de frutos secos en explotación en la región del Alto Valle, es acerca de la producción de nogales en Neuquén en 2014, que ascendía a 16.74 ha (Dirección Provincial de Estadísticas y Censos de la Provincia de Neuquén, 2014). En la actualidad, la superficie plantada con nogales y avellanos en Río Negro asciende a 1700.68 ha y en Neuquén alcanza las 264.63 ha (Consejo Federal de Frutos Secos, 2017). El incremento en la superficie sembrada se aproximaría a 779 ha, es decir, 66\% entre 2010 y 2017. Si bien no puede afirmarse que sea el único factor explicativo, la mayor visibilidad del clúster y las condiciones favorables que se crearon a partir de la asociación han fomentado la actividad.

Este aumento de la superficie implantada fue acompañado por un incremento en el rendimiento por hectárea en ambos cultivos, al menos para las regiones comprendidas en la provincia de Río Negro, que es sobre la que se cuenta con información precisa. En el caso de los nogales, el aumento fue de 660 kilogramos $(\mathrm{kg})$ por hectárea, pasando de 1.16 a 1.78 toneladas $(\mathrm{t})$ por ha. En los avellanos el aumento fue de $360 \mathrm{~kg}$ por hectárea, de 0.16 a $0.52 \mathrm{t} / \mathrm{ha}$. Éste no se debe sólo a mejores prácticas, pues en 2010, 85\% de los avellanos se encontraba todavía sin producir. La plantación de nogales para ese 2010 estaba más avanzada, pero tanto en Valle Medio como en Valle Inferior sólo $20 \%$ de la totalidad de la plantación se encontraba en plena producción. Teniendo en cuenta que no han existido inclemencias climáticas que afecten de forma crítica la estructura de plantación de los nogales, es deducible que la mayor productividad provenga de la mayor cantidad de plantas que maduraron hacia la producción media (de 1.3 a $1.5 \mathrm{t} / \mathrm{ha}$ ) o plena $(2.3 \mathrm{t} / \mathrm{ha}$ ).

Un indicador que permite deducir que el aumento en el rendimiento no sólo se debería a la maduración, es el incremento en el personal técnico disponible para asesoramiento. Previo a la iniciativa del clúster había sólo tres técnicos de INTA que realizaban alguna actividad relacionada con los frutos secos. En la actualidad, INTA asignó seis técnicos a la producción regional de frutos secos, mientras que el Centro PYME Adeneu cuenta con dos técnicos, y hay cuatro técnicos independientes que ofrecen sus servicios en el Alto Valle y el Valle Inferior, dos de los cuales trabajan con grupos de Cambio Rural vinculados con 
la asociación. Este incremento en la oferta de servicios especializados es un indicio del aumento de su demanda y podría estar asociado con mejoras en las prácticas de producción y en el mantenimiento de las plantas. Esto refuerza el análisis que se hizo antes sobre la calidad y la cantidad de información y la valoración que los productores hicieron al respecto.

Figura 4. Impacto sobre el territorio

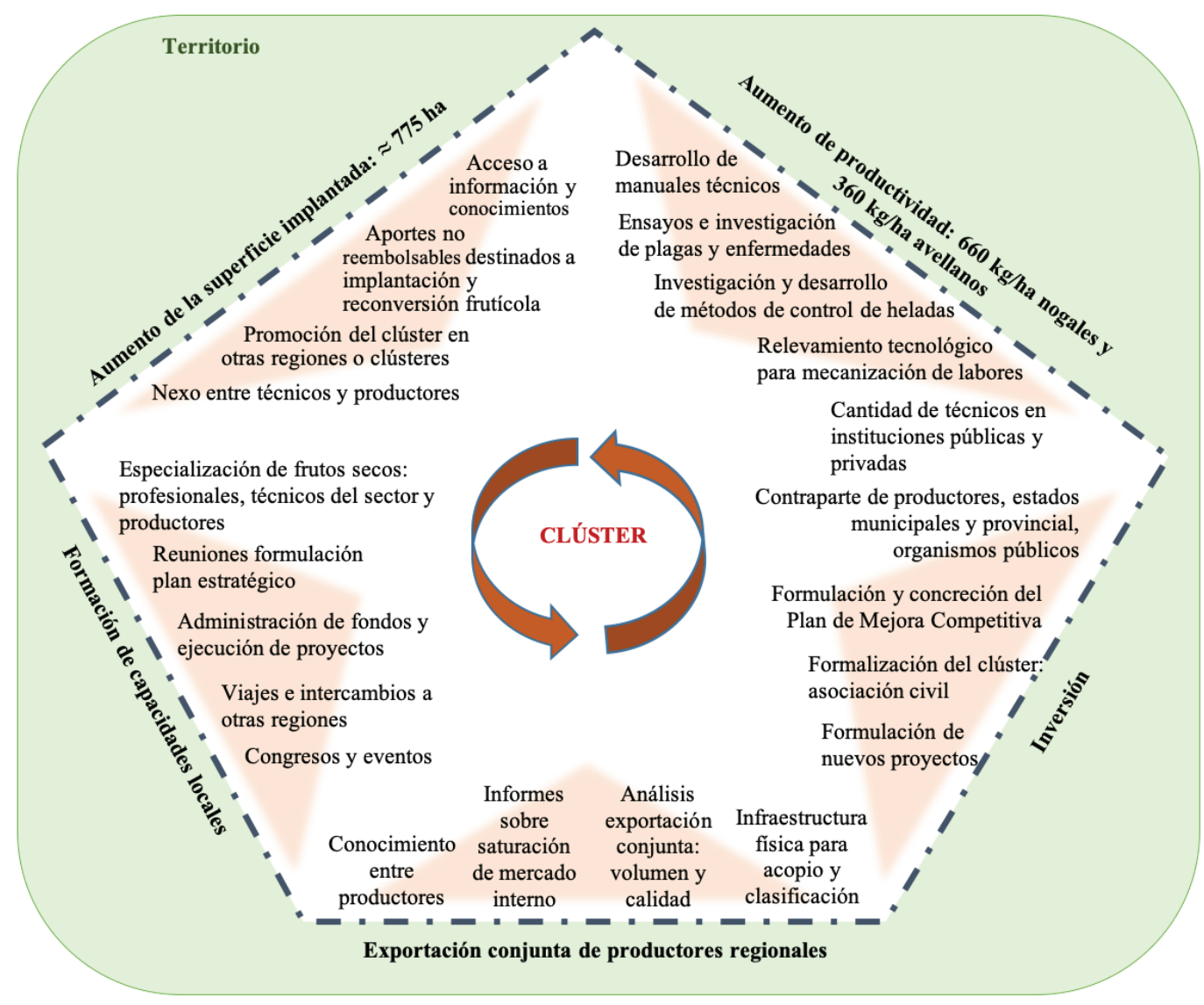

Fuente: elaboración propia.

Por otro lado, en las universidades vinculadas se cuenta con 10 profesionales que realizan actividades de investigación y desarrollo sobre derivados de frutos secos y sobre los sistemas de riego utilizados. Además, se creó la carrera universitaria Especialización de Frutos Secos con resolución ministerial en 2017, y que ha contado con dos cohortes, la primera de 23 estudiantes y la segunda de 6 , aunque con baja tasa de egreso. Además, al menos 16 productores tomaron los cursos de la especialización en calidad de alumnos vocacionales. 
A diferencia de las variables de superficie sembrada y de productividad, en el caso del nivel de inversión existen algunos datos que dan cuenta de la influencia de la asociación. A través de la Iniciativa de Desarrollo de Clústeres del Ministerio de Agroindustria, se concretaron inversiones de carácter no reintegrable por un monto de 600000 dólares entre 2011 y 2017. Además, entre 2011 y 2014 se invirtieron 500000 dólares con el objeto de realizar la formulación y posterior ejecución de los proyectos del PMC, cuyos principales destinos fueron la adquisición de maquinarias, infraestructura, equipamiento, fortalecimiento institucional, investigación y desarrollo. Como contraparte, los actores del clúster debieron movilizar un monto aproximado de 1100000 dólares que comprendía aportes en dinero, capital y recursos humanos, entre otros.

Entre 2013 y 2017, el Ministerio de Agroindustria aportó alrededor de 200000 dólares con el fin de promover la inversión privada a través de aportes no retornables. Dicha cantidad complementó los bienes y servicios colectivos realizados en la primera etapa. En cambio, el sector privado debió invertir un valor aproximado de 740000 dólares. También, durante esos años, el mismo ministerio financió a la asociación con el objetivo de fortalecer el desarrollo institucional. El monto final fue de 64516 dólares, destinado a honorarios de profesionales, sueldos e insumos de oficina.

Entre 2016 y 2018 se ejecutó el proyecto Centro de Servicios para el Agregado de Valor, cuyo monto ascendió a 200000 dólares. Del mismo modo que en las otras inversiones, los beneficiarios debieron aportar para su ejecución. Los aportes se realizaron en capital, recursos humanos y en la cesión en comodato del terreno e infraestructura.

Las inversiones mencionadas hasta aquí se vinculan directamente a la creación de la asociación, ya que los beneficiarios directos fueron los actores e instituciones que la componen. Además, la asociación fue beneficiada, aunque de modo indirecto, por otras inversiones realizadas en materia de agregado de valor (desarrollo del aceite y las harinas) y de control remoto para sistemas de riego por la Universidad Nacional de Río Negro entre 2012 y 2016. Se destinaron algo más de 600000 dólares en maquinarias, formación de capital humano y desarrollo de tecnología.

En cuanto a la adquisición de experiencia exportadora, no se ha tenido acceso a los datos de la evolución de las exportaciones de frutos secos de la Norpatagonia. Sin embargo, mediante las entrevistas se supo que sólo dos empresas exportan parte de su producción. Una de ellas participa de manera activa en la asociación y la otra ha estado involucrada de forma marginal, aunque bien dispuesta a responder consultas específicas por parte de los actores del clúster.

Lo relevante para el análisis fue que durante 2018 se produjo el primer caso de exportación conjunta, en el que participaron ocho productores de frutos secos de la Norpatagonia. La iniciativa surgió a partir de la necesidad de diversificar mercados para no saturar el mercado regional, situación que ha quedado registrada en actas de reuniones de la asociación durante 2015 y 2016. La infraestructura física que se utilizó para acopiar, clasificar por tamaño y calidad y consolidar cargas, fue la antes mencionada planta de acondicionamiento y empaque de Valle Medio. 


\section{Consideraciones finales}

En relación con la fruticultura tradicional de peras y manzanas, la producción de frutos secos es una actividad relativamente nueva en Río Negro y Neuquén. La Asociación Civil Clúster de Frutos Secos de la Norpatagonia nació como una iniciativa del Estado nacional argentino. Sin embargo, en el territorio ya se contaba con experiencias similares y existía una red de instituciones y organismos de apoyo. De todas formas, fue a partir de aquel apoyo gubernamental que se expandió geográficamente.

Es escasa la información disponible sobre esta rama productiva, fundamentalmente sobre el impacto atribuible al desarrollo del clúster y, en particular, a la Asociación que engloba la mayor parte de las instituciones y productores. El objetivo del trabajo fue cubrir de manera parcial este vacío a través de una evaluación exploratoria. Por eso el análisis se concentró en dos fuentes de mejoras del desempeño y en cinco variables mensurables de impacto.

El acceso, el caudal y la calidad de la información que ha circulado dentro del clúster son aspectos que han sido valorados de forma favorable por los participantes. En cierto modo, ellos asumieron parte de la responsabilidad por los problemas observados, fundamentalmente en la coordinación, y consideran necesario sostener los vínculos formales e informales construidos.

Los problemas de coordinación tienen una estrecha relación con el escaso financiamiento disponible en la actualidad. El acceso a éste es una variable clave para el desempeño y la continuidad de la asociación. La autosostenibilidad a partir de una mayor participación de los productores sería la solución. Ante la imposibilidad de aportes monetarios significativos por parte de los productores, en su mayoría pequeños y medianos, se podrían generar ingresos a partir de la prestación de servicios a través de la Planta de Acondicionamiento y Conservación de Valle Medio y del Centro de Servicios para el agregado de valor de Valle Inferior.

Si bien se observó un impacto positivo en el territorio en todas las variables, sólo en algunas es posible vincular a la asociación de manera directa con el resultado observado. Es el caso de la inversión pública directa en infraestructura para el desarrollo poscosecha y agregado de valor, el fomento a la implantación y la reconversión frutícola, el aumento en la cantidad de técnicos e instituciones que apoyan el clúster, así como la generación de conocimiento y trasferencia. La asociación ha contribuido a formar un entorno favorable para los actores e instituciones que la integran, así como para otros actores interesados en involucrarse en la actividad.

Se hizo evidente la necesidad de confeccionar estadísticas relacionadas con variables cualitativas y cuantitativas que permitan realizar una evaluación periódica del grado de avance de los proyectos y de sus efectos. Las iniciativas mixtas de esta naturaleza deben prever la generación de indicadores que contribuyan a evaluar las mejoras en la competitividad de las empresas y el desarrollo de los territorios involucrados. Sólo con esta previsión y los recursos necesarios, se podrá emprender un proceso de aprendizaje y retroalimentación necesario para la mejora competitiva a largo plazo. 


\section{Referencias}

Alba, M., Bedascarrasbure, E., y García Álvarez-Coque, J. M. (2008). Innovación y desarrollo social en el medio rural argentino. El caso del clúster Apícola del Noroeste y Centro Argentino. Trabajo presentado en el VII Coloquio Iberico de Estudos Rurais, Cultura, Innovación y Territorio, Coimbra, Portugal.

Alderete, M. V. (2013). La influencia del clúster vitivinícola en el desarrollo local: el caso de Mendoza (Argentina) y Serra Gaucha (Brasil). Revista de Economía, 39(2), 112-138.

Alemán Baires, B. Y. (2004). Diseño de una guía metodológica para la formación de un clúster publicitario edilicio para las alcaldías municipales del departamento de Santa Ana (tesis de Licenciatura en Mercadotecnia y Publicidad). Universidad Francisco Gavidia. Recuperada de http://ri.ufg.edu.sv/jspui/ handle/11592/7884

Asociación Civil del Clúster de Frutos Secos de la Norpatagonia. (2016). Informe de cierre del Clúster de Frutos Secos de la Norpatagonia. Documento interno inédito.

Avellá, S., Landriscini, G., y Preiss, L. O. (2018). Complejo frutícola de Río Negro y Neuquén. Exportaciones, principales competidores y factores que condicionan la competitividad. Revista Interdisciplinaria de Estudios Agrarios, 48, 93-126.

Becerra Rodríguez, F., Serna Gómez, H., y Naranjo Valencia, J. (2013). Redes empresariales locales, investigación y desarrollo e innovación en la empresa. Cluster de herramientas de Caldas, Colombia. Estudios Gerenciales, 29(127), 247-257. doi: https://doi.org/10.1016/j.estger.2013.05.013

Banco Interamericano de Desarrollo (BID). (2013). El distrito productivo de la maquinaria agrícola en Las Parejas: un estudio desde la perspectiva del desarrollo económico local. ConectaDEL. Recuperado de http://www.conectadel.org/wp-content/uploads/downloads/2013/09/Estudio-de-Caso-Las-Parejas-final.pdf

Bongiovanni, R., Giletta, M. , y Barberis, N. (2008). El clúster del maní en Córdoba. En R. Bongiovanni (ed.), Economía de los cultivos industriales: algodón, caña de azúcar, maní, tabaco, té y yerba mate (pp. 45-50). Manfredi, Córdoba, Argentina: INTA. Recuperado de https://inta.gob.ar/sites/default/files/ script-tmp-economa_de_los_cultivos_industriales_inta.pdf

Consejo Federal de Frutos Secos. (2016). Acta de conformación. Documento interno inédito. Buenos Aires, Ministerio de Agricultura, Ganadería y Pesca.

Consejo Federal de Frutos Secos. (2017). Informe final del relevamiento nacional de frutos secos. Mendoza, Universidad Nacional de Cuyo.

Costamagna, P., y Rossi, S. P. (2015). Enfoque, estrategias e información para el desarrollo territorial. Los aprendizajes desde ConectaDEL. Buenos Aires: ConectaDEL y Fondo Multilateral de Inversiones. Recuperado de https: / / otu. opp.gub.uy/sites/default/files/docsBiblioteca/Conectadel_web_150final. pdf

Dini, M., Ferraro, C., y Gasaly, C. (2007). Pymes y articulación productiva. Resultados y lecciones a partir de experiencias en América Latina. Santia- 
go de Chile: CEPAL, División de Desarrollo Productivo y Empresarial. Recuperado de https://repositorio.cepal.org/bitstream/handle/11362/4575/1/ S0700832_es.pdf

Dirección Provincial de Estadísticas y Censos de la Provincia de Neuquén. (2014). Encuesta Provincial Frutihortícola 2014. Recuperado de https:// www.estadisticaneuquen.gob.ar/static/archivos/Publicaciones/Fruticola/ encuesta_fruticola_2014.pdf

Dirven, M. (2006). Acción conjunta en los clústers: entre la teoría y los estudios de caso. Trabajo presentado en el Seminario Internacional "Territorios Rurales en Movimiento". RIMSP, Centro Latinoamericano para el Desarrollo Rural. Santiago de Chile, Chile.

Enright, M., y Ffowcs-Williams, I. (2000). Local partnership, clusters and SME globalisation. Background Report for Conference for Ministers responsible for SMEs and Industry Ministers. Enhancing the Competitiveness of SMEs in the Global Economy: Strategies and Policies. Organisation for Economic Co-operation and Development. Bolonia, Italia, 14-15.

Etzkowitz, H., y Leydesdorff, L. (1997). Introduction to special issue on science policy dimensions of the Triple Helix of university-industry-government relations. Science and Public Policy, 24(1), 2-5. doi: https://doi.org/10.1093/ spp/24.1.2

Fernández, V., Amin, A. y Vigil, J. (2008). Repensando el desarrollo regional. Contribuciones globales para una estrategia latinoamericana. Buenos Aires: Miño y Dávila.

Ferraro, C., y Stumpo, G. (2010). Políticas de apoyo a las pymes en América Latina. Entre avances innovadores y desafíos institucionales. Serie Libros de la CEPAL, Santiago de Chile: CEPAL. Recuperado de https: / /www.cepal.org/ es/publicaciones/2552-politicas-apoyo-pyme-america-latina-avances-innovadores-desafios-institucionales

Fucks, M., y Yoguel, G. (2003). Desarrollo de redes de conocimiento. Estudios sobre empleo componente D Préstamo BID 925/OC-AR. Pre II. Buenos Aires: Coordinación del Estudio, Oficina de la CEPAL-ONU.

Gálvez-Nogales, E. (2010). Agro-based clusters in developing countries: staying competitive in a globalized economy. Agricultural management, marketing and finance (Occasional Papers, no. 25). Roma: FAO. Recuperado de http:// www.fao.org/3/i1560e/i1560e.pdf

Gertler, J., Martínez, S., Premand, P., Rawlings, L., y Vermeersch, C. (2011). La evaluación del impacto en la práctica. Banco Internacional de Reconstrucción y Fomento/Banco Mundial. Washington D. C. Recuperado de https://publications.iadb.org/publications/spanish/document/La-evaluaci\%C3\%B3n-de-impacto-en-la-pr\%C3\%A1ctica-Segunda-edici\%C3\%B3n.pdf

González, G., Tedesco, L., y Sastre, M. S. (2016). Evolución del entorno de negocios y análisis económico de la producción de aceite de oliva virgen extra en el sudoeste bonaerense. Faces, 22(47), 63-79.

González Gómez, D. (2011). Asociatividad productiva. Modelo de la pirámide modular para el análisis local de grupos asociados (ALGA). Primer Foro Mundial de Agencias de Desarrollo Local. 
Grueso Hinostroza, M. P., Merlín, P., Gómez, J. H., y Quintero, L. (2009). Procesos de asociatividad empresarial: aproximaciones conceptuales e impacto económico, social y organizacional. Bogotá: Editorial Universidad del Rosario.

Iglesias, D., Thornton, R., Rocco, E., Saravia, D., y Paggi, D. (2006). Estudio de las PyMES agroalimentarias lácteas de Gral. Campos: un sistema agroalimentario localizado en La Pampa, Argentina. Trabajo presentado en ALTER. III Congreso Internacional Food and Territories. Universidad Internacional de Andalucía. Baeza (Jaén), España. Recuperado de https://kipdf.com/martes-17-de-octubre-inscripciones-al-congreso_5ac935d41723dd6bf2a3af2a. html

Kataishi, R., Romano, S., y Valle, J. (2017). El Clúster de Pesca Artesanal de Tierra Del Fuego: diagnóstico y desafíos futuros. Ciência \& Trópico, 37(1), 257-280.

Lattuada, M. (2014). Las asociaciones económicas no cooperativas de la agricultura familiar. Algunas nociones y conceptos para su estudio y consolidación. Ciudad Autónoma de Buenos Aires: INTA, IICA. Recuperado de https://inta. gob.ar/sites/default/files/script-tmp-intaafnociones.pdf

Lozano Uvario, K., y Méndez Guardado, P. (2015). Clústers agroalimentarios: viabilidad y oportunidades para el caso de la industria alimentaria en Zapopan, Jalisco. En O. Serrano, E. Serena y L. A. Medina García, Pasado, presente y futuro de las regiones en México y su estudio (1-27). Ciudad de México: Asociación Mexicana de Ciencias para el Desarrollo Regional. Recuperado de http: / / ru.iiec.unam.mx/2823/1/Eje1-225-Lozano-Mendez.pdf

Maffioli, A., Pietrobelli, C., y Stucchi, R. (2016). The impact evaluation of cluster development programs. Methods and Practices. Washington, D. C.: IDB. Recuperado de https://publications.iadb.org/publications/english/ document/The-Impact-Evaluation-of-Cluster-Development-Programs-Methods-and-Practices.pdf

Martínez-Carrasco Pleite, F., y Martínez Paz, J. M. (2012). El clúster agroalimentario de la región de Murcia. Cuadernos de Estudios Agroalimentarios, 2, 175-198.

Martínez-Paz, J. M., Martínez-Carrasco, F., y Dios Palomares, R. (2005). La industria de conservas vegetales en la región de Murcia. Análisis de eficiencia técnica. Revista de Estudios Regionales, 73, 141-158.

Meyer-Stamer, J., y Harmes-Liedtke, U. (2005). Cómo promover clústers (Mesopartner Documento de Trabajo. Recuperado de http: / /iberpyme.sela.org/ Documentos/comopromoverclusters.pdf

Niembro, A. (2017). Hacia una primera tipología de los sistemas regionales de innovación en Argentina. Investigaciones Regionales, 38, 117-149.

Organización para la Cooperación y el Desarrollo Económico (OECD). (2005). Business clusters: promoting enterprise in Central and Eastern Europe. París: OECD Publishing. Recuperado de https: / / read.oecd-ilibrary.org/employment/business-clusters_9789264007116-en\#page1

Örjan, S., Lindquist, G., y Ketels, C. (2003). The Cluster Initiative Greenbook. Estocolmo: Ivory Tower. 
Palau, H., y Napolitano, G. (2011). Como intervenir en iniciativas clústeres agroalimentarias en países en desarrollo. El método EPECA. Trabajo presentado en la VIII International Agribusiness PAA-PENSA Conference. Buenos Aires.

Perdomo, J., y Malaver, F. (2003). Metodología para la referenciación competitiva de clústers estratégicos regionales. Bogotá: Centro de Investigaciones para el Desarrollo (CID), Universidad Nacional de Colombia.

Pietrobelli, C., y Rabellotti, R. (2006). Clusters and value chains in Latin America: in search of an integrated approach. En Pietrobelli, C. y Rabellotti, R. (eds.), Upgrading to Compete Global Value Chains, Clusters, and SMEs in Latin America (pp. 1-40). Washington, D. C.: IDB. Recuperado de http:// www.ucar.gob.ar/index.php/biblioteca-multimedia/buscar-publicaciones/24-documentos/399-plan-de-mejora-competitiva-cluster-de-frutos-secos-de-rio-negro

Pomareda B., C. y Arias S., J. (2007). Indicadores de desempeño de cadenas agroalimentarias: metodología y caso ilustrativo. Lima: IICA. Recuperado de https://www.researchgate.net/publication/275042103_Indicadores_de_ desempeno_de_cadenas_agroalimentarias_Metodologia_y_caso_ilustrativo

Porter, M. E., Furman, J. L., y Stern, S. (2000). Los factores impulsores de la capacidad innovadora nacional: implicaciones para España y América Latina. Claves de la Economía Mundial, 1, 78-88.

Programa de Servicios Agrícolas Provinciales (PROSAP). (2010). Plan de Mejora Competitiva Clúster de Frutos Secos de Río Negro. Viedma, Río Negro: PROSAP.

Ramos, J. (1998). A development strategy founded on natural resource-based production clusters. Revista CEPAL.

Rivera-León, L., y Kataishi, R. (2010). Collaboration networks for innovation and socio-economic development: European and Latin American perspectives on digital ecosystems research, local readiness, deployment strategies, and their policy implications. En F. A. B. Colugnati, L. C. R. Lopes y S. F. A. Barretto (eds.), Digital Ecosystems. Third International Conference, OPAALS 2010, Aracuju, Sergipe, Brasil (Revised Selected Papers). Berlin, Heidelberg: Springer. doi: https://doi.org/10.1007/978-3-642-14859-0_1

Schmitz, H., y Nadvi, K. (1999). Clustering and industrialization: introduction. World Development, 27(9), 1503-1514.

Tagliani, P. (2016). Tópicos de políticas públicas: desarrollo económico de la provincia de Río Negro. Recuperado de https://admin.curza.uncoma.edu. ar/wp-content/uploads/2016/07/PoliticasPublicas-Tagliani-1.pdf

Tedesco, L. (2009). El rol del estado en torno a la formación de complejos agroindustriales (Documento de Trabajo del Observatorio de Políticas Públicas para la Agroindustria y el Desarrollo (OPPAD). Universidad Nacional del Sur, Argentina. Recuperado de http://www.oppad.uns.edu.ar/docs/trabajos/congresos/Estado\%20y\%20clusters.pdf

Unidad para el Cambio Rural (UCAR). (2014). Manual de Organización y Funciones. Ministerio de Agricultura, Ganadería y Pesca. Recuperado de http: / / www. prosap.gov.ar/webDocs / ManualOrganizacionYFuncionesUCAR-Junio2014.pdf 
Vera Díaz, V. (2010). Diseño de una metodología de evaluación de impacto de postítulos para la clusterización sectorial. Caso diplomado ganadero Región de Aysén (tesis). Repositorio Académico de la Universidad de Chile. Recuperado de http://repositorio.uchile.cl/handle/2250/103822

Vera Garnica, J. (2009). Clúster del Salmón en Chile: análisis de los factores de competitividad a escala internacional. Revista Venezolana de Gerencia, 14(47), 343-370.

Villegas Nigra, H. M., Miñón, D. J., Di Nardo, Y., y Carusso, G. (2014). Posicionamiento de frutos secos rionegrinos en el mercado interno. Análisis Región Patagónica. En H. M. Villegas Nigra y D. J. Miñón (comps.). Territorios y producción en el nordeste de la Patagonia (pp. 87-104). Viedma, Río Negro, Argentina: Estación Experimental INTA Valle Inferior Convenio Provincia de Río Negro. 